\title{
Crumb Rubber Concrete Deterioration Caused by Sulphate Attack
}

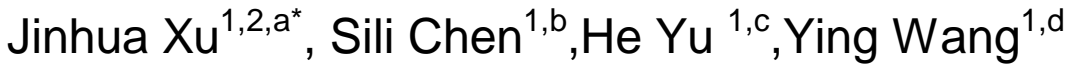 \\ ${ }^{1}$ School of Architecture \& Civil Engineering, Shenyang University of Technology, No.111, Shenliao \\ West Road, Economic \& Technological Development Zone, Shenyang, 110870, P.R.China \\ ${ }^{2}$ School of Resources \& Civil Engineering, Northeastern University, No.11, Lane 3, WenHua Road, \\ HePing District, Shenyang, Liaoning, 110819, P.R.China \\ axjhnet@sina.com, bchen1458@sina.com, cyhdut9954053@163.com, ${ }^{\mathrm{a}}$ ren-jianwei@hotmail.com
}

Keywords: Crumb rubber concrete, sulphate attack, corrosion coefficient.

Abstract. An exhaustive study should be carried on Crumb Rubber Concrete deterioration caused by sulphate attack in this paper. the crumbed tire rubber powder were used to replace fine aggregates of concrete, whose grain size is $0.28 \mathrm{~mm}$. The replacement levels were $5 \%, 10 \%, 15 \%$ and $20 \%$ by volume of the fine aggregates. It is evaluated to effect of sulphate attack on appearance and compressive strength of crumb rubber concrete. The research shows that appropriate proportional fine aggregate replaced by rubber powder can improve resistance to sulphate attack of concrete, especially mixing $5 \%$ and $10 \%$ rubber powder. But too much rubber content results in decreasing its performance.

\section{Introduction}

With the economic development, waste rubber become a major component of solid waste. Especially automotive industry, more and more waste rubber tires are produced. with a portion of aggregates replaced by tire rubber particles, crumb rubber concrete is an innovative and effective way of using recycled tire rubbers. Many scholars expressed great interest in the use of crumb rubber concrete in civil engineering. Research suggested crumb rubber concrete has a lot of advantages, such as lower density, increased toughness and desired ductility. The use of tire rubber in cement composites would not only make good use of the solid waste material but also can improves certain properties for Portland concrete ${ }^{[1]}$. In recent years, rubber aggregate concrete has been given much attention in civil engineering. One of the most promising is road and bridge pavements ${ }^{[2]}$. Many scholars focused on fundamental mechanical performances of crumb rubber Concrete crumb rubber concrete and have obtained a lot of research achievements in civil engineering. But its durability is another key issue. Durability of Rubberized Mortar and Concrete was researched by Topcu ${ }^{[3]}$. Most soils contain some sulphate in the form of gypsum. It is harmless to concrete. Resistance to sulphate attack of concrete is considered as one of the most important index to evaluate durability of concrete ${ }^{[4]}$. In the paper, Experimental study on crumb rubber concrete deterioration caused by sulphate attack is conducted, which Portland cement concrete is mixed four kinds of content rubber powder.

\section{Experiment Study}

Materials. Type I ordinary Portland cement meeting the requirements of ASTM was used in the preparation of rubber concrete specimens. River sand with fineness modulus of 2.55 and a specific gravity of 2.6 was used as fine aggregate. Crushed limestone with a nominal maximum size of $25 \mathrm{~mm}$ was used as coarse aggregate. The coarse aggregate met the grading requirements and its specific gravity was 2.65. Rubber powder from waste tire is mixed in Portland cement concrete. The biggest grain size of rubber powder is $0.28 \mathrm{~mm}$.

Mixture proportion. Tests were carried out to investigate the behavior of different concretes with rubber content $(\%)$. The mixes were prepared by replacing part volume of river sand with rubber powder at five different replacement levels of $0,5,1015$ and 20\% and were named respectively C-0, 
C-5, C-10, C-15 and C-20. The mixture proportions of crumb rubber concrete sets are listed in Table 1.

Table 1 Mixture proportion of crumb rubber concrete

\begin{tabular}{ccccccccc}
\hline Group & $\begin{array}{c}\text { Rubber } \\
\text { content }\end{array}$ & $W / C$ & $S_{p}$ & $\begin{array}{c}\text { Water } \\
\left(\mathrm{kg} \mathrm{m}^{-3}\right)\end{array}$ & $\begin{array}{c}\text { Cement } \\
\left(\mathrm{kg} \mathrm{m}^{-3}\right)\end{array}$ & $\begin{array}{c}\text { Sand } \\
\left(\mathrm{kg} \mathrm{m}^{-3}\right)\end{array}$ & $\begin{array}{c}\text { Gravel } \\
\left(\mathrm{kg} \mathrm{m}^{-3}\right)\end{array}$ & $\begin{array}{c}\text { Rubber } \\
\left(\mathrm{kg} \mathrm{m}^{-3}\right)\end{array}$ \\
\hline C-0 & $0 \%$ & 0.4 & 0.33 & 185 & 463 & 606 & 1228 & 13 \\
C-5 & $5 \%$ & 0.4 & 0.34 & 185 & 463 & 601 & 1228 & 12 \\
C-10 & $10 \%$ & 0.4 & 0.33 & 185 & 463 & 545 & 1228 & 24 \\
C-15 & $15 \%$ & 0.4 & 0.36 & 185 & 463 & 587 & 1228 & 41 \\
C-20 & $20 \%$ & 0.4 & 0.35 & 185 & 463 & 529 & 1228 & 52 \\
\hline
\end{tabular}

Specimens. Rubber concrete specimens were produced on base of mixture proportion. 100 $\mathrm{mm} \times 100 \mathrm{~mm} \times 100 \mathrm{~mm}$ cubes specimens were cast for each mixture and compacted using a vibrating table. Test specimens were demoulded $24 \mathrm{~h}$ after casting and then water cured for 28 days under temperature $20 \pm 1^{\circ} \mathrm{C}$ and humidity $95 \%$.

Experiments. Standard testing procedures according to Test Methods of Cement and Concrete for Highway Engineering (JTG E30-2005) were used to evaluate the hardened concrete ${ }^{[5]}$. Investigation of harden concrete included determining the 28 days compressive strength. the five groups specimens were placed into plastic boxes, filled with $5 \% \mathrm{Na}_{2} \mathrm{SO}_{4}$ solution. It is shown that crumb rubber concrete attacked by sulphate in Fig. 1. The specimens are immersed in the solution for 30d, 60d, $90 \mathrm{~d}$ and $120 \mathrm{~d}$. Then, the specimens are taken out from plastic boxes, observed and carried out compression test, which is shown in Fig. 2.

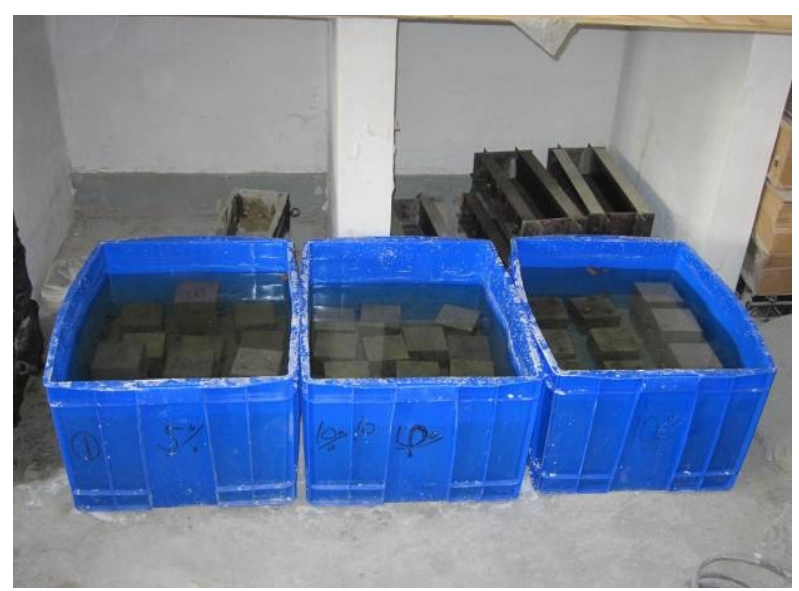

Fig. 1 Specimens of sulphate attacking

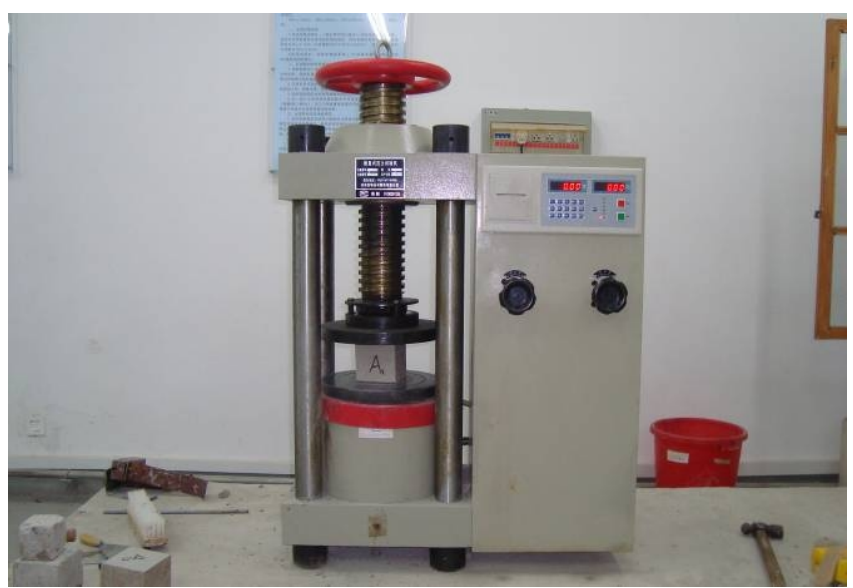

Fig. 2 Test of compressive strength

\section{Results and discussion}

Effect of sulphate attack on appearance of crumb rubber concrete. with corrosion age increasing, appearance of crumb rubber concrete specimens Gradually changes and the specimens attacked 120 days by $\mathrm{Na}_{2} \mathrm{SO}_{4}$ solution are shown in Fig. 3. It is indicated that sulphate attack is accompanied by expansion and frequently by cracking. There is no distinctive pattern of cracks and it is random. Where the concrete has heaved or bulged, the cracks often radiate from the centre of movement. From Fig.3, It can be seen that the $5 \%$ and $15 \%$ in volume replacements with rubber powder gave satisfying results whose appearance hardly varies. When Portland cement paste comes into contact with sulphate ions, the alumina-containing hydrates, in the presence of calcium hydroxide, are converted to ettringite. There is general agreement that the sulphate-related expansion in concrete is associated with ettringite. The mechanisms causing expansion. If the expansion pressure exceeds the tensile strength of the material at any point, it will cause local cracking. however, rubber is elastic material, and it can absorb 
the expansion energy caused by ettringite and, in this way, avoids structure failure. Therefore, mixing $5 \sim 10 \%$ rubber powder in concrete can obviously improve resistance to sulphate attack. But too much rubber content results in decreasing resistance to corrosion.

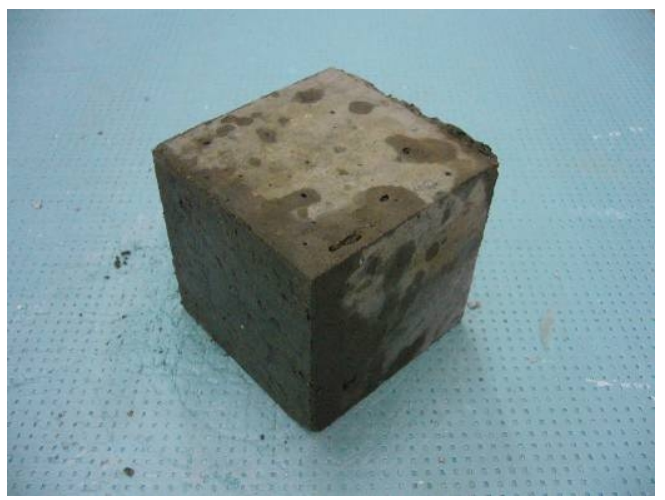

(a)C-5

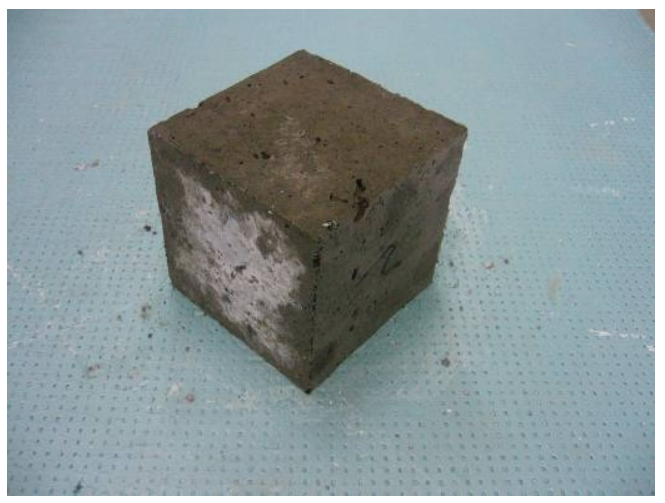

(c) $\mathrm{C}-15$

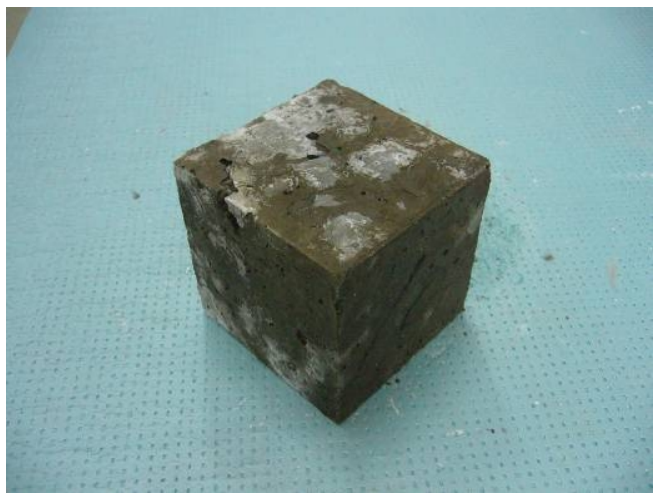

(b) $\mathrm{C}-10$

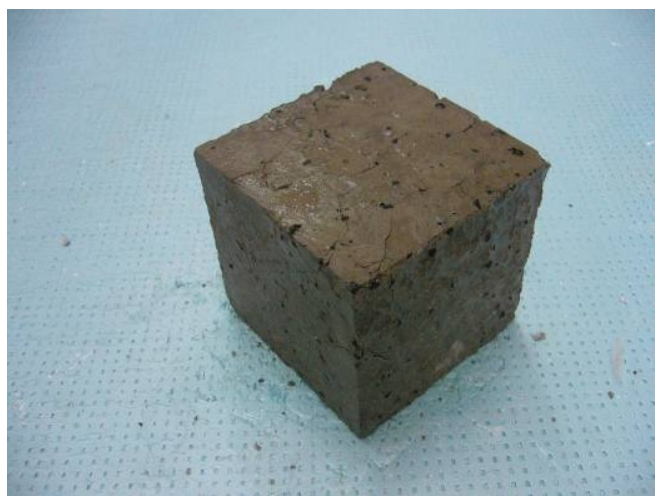

(d)C-20

Fig. 3 Specimens caused by sulphate attack

Effect of sulphate attack on compressive strength of crumb rubber concrete. After sulphate attack, effect of different percentages of rubber powder on the concrete compressive strength was evaluated and the results are shown in Table 2.

Table 2 Compressive strength of crumb rubber concrete after sulphate attack（MPa)

\begin{tabular}{cccccc}
\hline \multirow{2}{*}{ Group } & compressive & \multicolumn{5}{c}{ compressive strength of after sulphate attack } \\
& strength of 28d & 30d & 60d & 90d & 120d \\
\hline C-0 & 49.83 & 50.34 & 49.12 & 47.46 & 42.39 \\
C-5 & 49.13 & 53.49 & 51.52 & 46.37 & 45.12 \\
C-10 & 44.46 & 49.61 & 46.68 & 43.8 & 41.73 \\
C-15 & 40.46 & 44.95 & 42.17 & 38.25 & 35.26 \\
C-20 & 35.96 & 34.42 & 33.25 & 30.47 & 29.15 \\
\hline
\end{tabular}

In order to better analysizing Effect of sulphate attack on compressive strength of crumb rubber concrete, resistance to corrosion coefficient of compressive strength $K_{f i}$ is proposed and expressed by eq. 1.

$$
K_{f i}=\frac{f_{c i}}{f_{c 0}} \times 100
$$

Where $K_{f i}$ is resistance to corrosion coefficient of compressive strength at the stage $i$, and $f_{c i}$ is compressive strength at the stage $i$, and $f_{c o}$ is compressive strength at 28 days. $K_{f i}$ of different stages of crumb rubber concrete are shown in Fig. 4. It can be clearly seen that rubber content played most 
important role to resistance to sulphate attack. mixture proportion with rubber content of 5\% will achieve larger compressive strength and better resistance to sulphate attack of crumb rubber concrete.

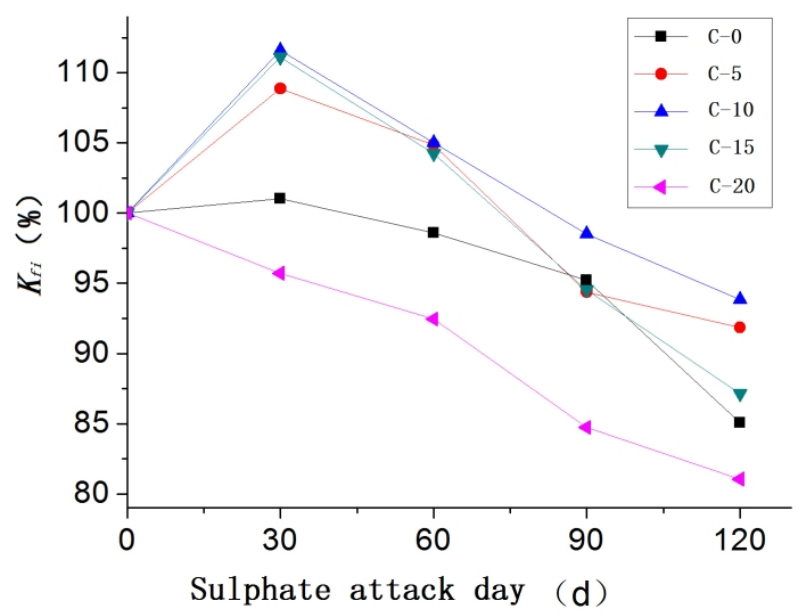

Fig. 4 Resistance to corrosion coefficient of compressive strength $K_{f i}$

\section{Conclusion}

Based on this study, the following conclusions can be drawn:

(1) The 5 and $15 \%$ in volume replacements with rubber powder in concrete can obviously improve resistance to sulphate attack. But too much rubber content results in decreasing its performance.

(2) Mixture proportion with rubber content of 5\% will achieve larger compressive strength and better resistance to sulphate attack of crumb rubber concrete.

(3) Mixture proportion with rubber content of $20 \%$ will be unfavorable to mechanical performance of crumb rubber concrete.

\section{Acknowledgements}

This work was financially sponsored by Education Department Fund of Liaoning Province, China (No. L2012039) and supported by National Natural Science Fund of China (No. 51279109).

\section{References}

[1] L. Zheng, H. X. Sharon and Y. Yuan: submitted to Journal of Materials in Civil Engineering (2008).

[2] L. Basheer, J. Kropp and D. J.Cleland: submitted to Construction and Building Materials (2001).

[3] I. B. Topcu and A. Demir: submitted to Journal of materials in Civil Engineering (2007).

[4] P. Hu, H. Zhu, Y. Wang: submitted to Journal of Tianjin University of Technology (in chinese), 2006, 22(4), 8-12.

[5] China Ministry of Communications Highway Scientific Research Institute. JTG E30-2005 Test Methods of Cement and Concrete for Highway Engineering (in chinese). Beijing: China Communications Press, 2005. 